\title{
PRODUÇÃO E MASSA SECA DE CULTURAS EM ROTAÇÃO EM DIFERENTES MANEJO DO SOLO EM ÁREAS DE REFORMA DE CANAVIAL NO OESTE PAULISTA
}

MATEUS, Gustavo Pavan ${ }^{1}$ ARAÚJO, Humberto Sampaio ${ }^{2}$ MÜLLER, Rafael do $\mathrm{Val}^{3}$ CRUSCIOL, Carlos Alexandre Costa ${ }^{4}$ BORGES, Wander Luis Barbosa

RESUMO: O oeste paulista é caracterizado pela recente expansão da canavicultura, ocupando terras de pastagens e cultivos de cereais. Essa região é caracterizada por solos de textura arenosa, alta demanda evapotranspirativa e períodos de déficit hídrico durante a estação chuvosa. O presente trabalho foi desenvolvido no Pólo Regional do Extremo Oeste, em Andradina-SP,com o objetivo de avaliar a produtividade da culturas combinado com diferentes sistemas de manejo do solo, em áreas de renovação de canavial. O experimento foi instalado em esquema de parcelas subdivididas, consistindo nos tratamentos preparo do solo (convencional, preparo reduzido e plantio direto) e 5 espécies utilizadas em sucessão, sendo uma associação de Crotalaria juncea L. e Dolichos lablab L.; amendoim, soja, milho, sorgo sacarino e pousio. Foram analisados a massa seca da parte aérea e a produtividade das culturas comerciais. Como resultado observou a baixa produtividade das culturas de sucessão devido ao déficit hídrico na fase de crescimento vegetativo e reprodutivo.

Palavras-chave: Rotação de culturas, cultivo conservacionista, palhada de cana.

SUMMARY: The west of São Paulo is characterized by the recent expansion of sugarcane, occupying pasture lands and cereal crops. This region is characterized by sandy soils, high evapotranspirative demand and periods of water deficit during the rainy season. This work was developed at the "Polo Regional do Extremo Oeste" in Andradina, SP, Brazil the objective of evaluating the yield crop combined with different soil management systems, in areas of sugarcane renewal. The split plot design was employed, was installed in a 3 X6 consisting of soil tillage treatments (conventional, low-tillage and no-tillage) and 5 species used in succession, being an association of Crotalaria juncea L. and Dolichos lablab L .; peanuts, soybeans, corn, sorghum, and fallow. Was analyzed dry shoot dry mass and yield components of crop rotation. As a result it observed the low yield of succession cultures due to the water deficit in the vegetative and reproductive growth phase.

Keywords: Crop rotation, low tillage, cane straw.

\section{INTRODUÇÃO}

A cana de açúcar é uma cultura de grande destaque no cenário do agronegócio brasileiro, ocupando em área de cultivo a quarta posição, perdendo apenas para pastagens, soja e milho. A região Centro-Sul são cultivados atualmente 9,4 milhões de hectares, sendo que mais de 60\% desta área cultivada concentra no Estado de São Paulo, tornando o maior produtor nacional de cana de açúcar (CANASAT, 2016), sendo que essa consolidação somente foi possível graças a expansão da cultura no oeste paulista nas últimas décadas. Após o plantio a produtividade da cana diminui ano a ano, até que depois de 5 anos em média se faz necessário o replantio da cultura. Tal prática agrícola é denominada de reforma do

\footnotetext{
${ }^{1}$ Pesquisador Científico Dr. APTA - Pólo Regional Extremo Oeste, Andradina-SP; Caixa Postal 67, Cep: 16900970, E-mail: gpmateus@apta.sp.gov.br

2 Pesquisador Científico Msc APTA - Pólo Regional Extremo Oeste, Andradina-SP;

3 Engenheiro Agrônomo, Msc, Andradina - SP;

${ }^{4}$ Professor, Dr. Faculdade de Ciências Agronômicas - UNESP - Campus de Botucatu;

${ }^{5}$ Pesquisador Científico, Dr. IAC - Centro de Seringueira e Sistemas Agroflorestais - Votuporanga-SP
} 
canavial (SANTIAGO; ROSSETTO, 2013). A baixa produtividade e longevidade são características presentes nas lavouras de cana do oeste paulista, sendo que nessa região as reformas dos canaviais costumam ser mais frequentes e, por se tratar de uma operação onerosa, aumenta os custos de produção e, por consequência, reduz a margem de lucro. A disponibilidade temporária de áreas aliada a possibilidade de maiores ganhos e mitigação de riscos promoveu a formação de parcerias entre as usinas e agricultores, incentivando a rotação de culturas com o cultivo de cereais em áreas de reforma de canavial.

Rotação de culturas é definida como sendo o cultivo alternado de diferentes espécies vegetais, em uma mesma gleba, sendo que ocorre o planejamento prévio das culturas de diferentes famílias, incluindo a prática da adubação verde (MASCARENHA et al., 1994).

As diferentes espécies vegetais possuem capacidade distintas de ciclagem de nutrientes (GARCIA et al., 2008) e de desenvolver em condições de solo mais compactados (CHEN; WEIL, 2011); dessa forma a prática da rotação proporciona melhorias nas propriedades físicas e químicas do solo, refletindo em maiores produtividades. Além desses benefícios, a rotação de culturas auxilia no controle de pragas, doenças e plantas daninhas, melhora a eficiência no uso da água, otimiza o uso de máquinas na propriedade, promove diversificação e consequentemente reduz os riscos da atividade agrícola (DERPSCH et al., 1991).

Maia; Ribeiro (2004) avaliaram as características químicas de um Argissolo Amarelo fragipânico, cultivado por 30 anos com cultivo contínuo de cana de açúcar, concluíram que o cultivo contínuo de cana de açúcar proporcionou reduções significativas de cálcio, magnésio, saturação por bases, capacidade de troca catiônica e matéria orgânica. Baquero et al. (2012) compararam as propriedades físicas de um Latossolo Vermelho eutroférrico sob condição de mata nativa e cultivado com cana de açúcar em experimento de longa duração e concluíram que as práticas de manejo da cana de açúcar promoviam alterações físicas do solo como aumento da resistência mecânica a penetração, densidade do solo e redução da macroporosidade em comparação à floresta nativa. Vários estudos têm mostrado os efeitos de leguminosas sobre a cultura da cana de açúcar. Ayala et al. (2003) obtiveram, variações de 14 a 84\% no rendimento da cana de açúcar utilizando diferentes espécies de leguminosas em rotação. Ambrosano et al. (2013) avaliaram o rendimento de 5 cortes de cana utilizando diferentes leguminosas em rotação, parcelas plantadas em rotação com crotalária juncea produziram $20 \mathrm{t} \mathrm{ha}^{-1}$ a mais na média dos cortes em comparação ao pousio. Nesse sentido, algumas pesquisas apontam que a capacidade de fixação biológica do nitrogênio pelas leguminosas podem contribuir com nutrição para o cultivo de cana de açúcar em sucessão, assim Ambrosano et al. (2005), trabalhando com técnicas isotópicas de ${ }^{15} \mathrm{~N}$, mostraram que aos 8 meses após o plantio da cana a maior percentagem de $\mathrm{N}$ provinha do adubo verde.

Por se tratar de uma cultura de ciclo longo é comum a ocorrência de períodos de menor disponibilidade hídrica que pode comprometer o desenvolvimento da cana de açúcar. Alleoni; Beuclair (1995) avaliaram o efeito da rotação com amendoim e milho sobre a variedade SP 70-1143, em Neossolo Quartzarênico em Piracicaba. Como resultado tem que o cultivo de cana em rotação com amendoim o conteúdo de água no solo foi de 10 a 50\% superior em comparação a rotação com milho, sendo que a causa provável consiste no aumento do teor de matéria em profundidade. Dessa forma, a escolha da espécie utilizada em rotação com a cana deve analisar ganhos fitotécnicos e econômicos entre as culturas.

A cultura da cana de açúcar é caracterizada pelo excesso de tráfego de máquinas pesadas. No ato da reforma do canavial é muito comum ocorrer operações motomecanizadas para o manejo do solo, principalmente com uso de grades e arados. Essa técnica tem o intuito de eliminar camadas compactadas e plantas daninhas, além de incorporar corretivos. Vale ressaltar também que essas operações ocorrem em períodos de maior precipitação, deixando o solo mais susceptível ao processo erosivo. Diante disto estudos têm sido feitos a fim de viabilizar o preparo reduzido do solo nos momentos de reforma do canavial. A 
definição de preparo reduzido relaciona-se com a quantidade de resíduos vegetais que permanecem na superfície após a operação motomecanizada, sendo que nessa condição deve permanecer ao menos $50 \%$ da quantidade de resíduos original (ASAE, 1997). Com o advento da colheita mecanizada sem despalha a fogo, o sistema de preparo reduzido passou a ser uma opção interessante, principalmente por apresentar vantagens como redução na população de plantas daninhas, menor quantidade de implementos, maior disponibilidade de máquinas, redução nos custos de preparo e da renovação do canavial, além de mitigar problemas com erosão (MUTTON, 1983; STOLF, 1985; CASAGRANDI, 1988; CONDE; DONZELLI, 1997; TORRES; VILLEGAS, 1988; PEREIRA; VELINI, 2003).

Assim a adoção de preparo reduzido com rotação de cultura durante a reforma do canavial pode contribuir redução de erosão com diminuição de custos e aumento de produtividade da cana. Trabalhos feitos por Duarte Júnior; Coelho (2008) concluem que a adoção o plantio direto e a rotação com adubos verdes na reforma, para as condições de Campos dos Goytacazes, propiciou TCH de 135,863 t ha ${ }^{-1}$, sendo $37 \%$ mais produtivo em comparação ao plantio convencional com vegetação espontânea.

O objetivo do presente trabalho foi avaliar a produtividade de diferentes culturas em diferentes sistemas de manejo do solo em áreas de reforma de canavial.

\section{MATERIAL E MÉTODO}

O experimento foi desenvolvido em condições de campo durante os anos de 2013/2014 e 2014/2015, em área experimental do Pólo Regional de Desenvolvimento Tecnológico dos Agronegócios do Extremo Oeste, sediado no município de Andradina-SP, localizado na região noroeste do Estado de São Paulo a 379 metros de altitude, latitude 205' S e longitude 5123' W. O clima, segundo a classificação Köpen, é tropical quente e úmido com inverno seco. A precipitação média anual é de 1150 mm e a temperatura média anual é de $23^{\circ} \mathrm{C}$. O solo do local foi classificado como Latossolo Vermelho Amarelo Distrófico Típico (EMPRAPA, 2006), o qual está sendo manejado a 4 anos com a cultura da cana-de-açúcar.

Os resultados das análises químicas do solo, na camada de 0-0,20 m e 0,20-0,40 m de profundidade, antes da instalação dos experimentos foram: $\mathrm{pH}\left(\mathrm{CaCl}_{2}\right)=4,9$ e 4,6; $\mathrm{P}_{\text {resina }}=8$ e $4 \mathrm{mg} \mathrm{dm}^{-3}$; matéria orgânica $=12$ e $10 \mathrm{~g} \mathrm{dm}^{-3} ; \mathrm{V} \%=46$ e 49; $\mathrm{H}+\mathrm{Al}=18$ e 16 mmol $_{\mathrm{c}} \mathrm{dm}^{-3} ; \mathrm{K} 1,1$ e $0,3 \mathrm{mmol}_{\mathrm{c}} \mathrm{dm}^{-3}$; $\mathrm{Ca}=10$ e $9 \mathrm{mmol}_{\mathrm{c}} \mathrm{dm}^{-3} ; \mathrm{Mg}=4$ e $6 \mathrm{mmol}_{\mathrm{c}} \mathrm{dm}^{-3} ; \mathrm{SB}=15,1$ e $15,3 \mathrm{mmol}_{\mathrm{c}} \mathrm{dm}^{-3} ; \mathrm{CTC}=33,1$ e 31,3 $\mathrm{mmol}_{\mathrm{c}}$ $\mathrm{dm}^{-3}$, as adubações e as correção do solo foram feitas de acordo com base na análise química do solo e segundo a recomendação de Raij et al. (1997) para as respectivas culturas.

O delineamento experimental utilizado foi em blocos casualizados em esquema de parcelas subdivididas, com 4 repetições. As parcelas foram constituídas por três sistemas de cultivo, sendo convencional (gradagem aradora + aração + niveladoras), preparo reduzido (dessecação + arado subsolador com rolo destorroador) e o plantio direto. As subparcelas foram constituídas por quatro culturas comerciais, sendo soja, milho, sorgo sacarino e amendoim, uma associação de adubos verdes (linhas intercaladas de Crotalaria juncea e Labelabe (Dolichos lablab L.), além do sistema pousio. Cada subparcela tem a dimensão de $70 \mathrm{~m}^{2}(7,0 \times 10,0 \mathrm{~m})$, sendo que para as avaliações foram consideradas as linhas centrais desprezando as duas linhas das extremidades.

O sistema de manejo convencional do solo, compreendeu uma gradagem intermediária (27/11/2013), visando destruição dos restos culturais, seguido de aração com arado de aivecas (02/12/2013), além de gradagem niveladora (03/12/2013). O preparo reduzido consistiu de uma passada de arado escarificador (28/11/2013) com 7 hastes e rolo destorroador (modelo AST/MATIC $450^{\circledR}$, marca Tatu-Marchesan), que trabalhou em profundidades de até $0,45 \mathrm{~m}$ nivelando razoavelmente o terreno e 
mantendo pelo menos 50\% dos resíduos. Em 03/12/2013 realizou-se a semeadura de todas as culturas por meio de semeadora de semeadura direta, modelo PST-3® Tatu-Marchesan.

As amostras para determinação da produção de matéria seca em $\left(\mathrm{kg} \mathrm{ha}^{-1}\right)$ foram picadas e secadas a $65^{\circ} \mathrm{C}$ por 72 horas, em estufa de ventilação forçada, sendo posteriormente obtida a massa de material seco.

No plantio da soja foi utilizado a cultivar Valiosa RR que foi semeada na densidade de 20 sementes por metro de sulco e espaçamento de 0,50 m entrelinhas, correspondendo à aproximadamente, 400.000 sementes $\mathrm{ha}^{-1}$. No florescimento pleno das plantas de soja (04/02/2014), correspondente ao estádio R2 na escala de Fehr et al. (1971), foi determinada a produção de matéria seca $\left(\mathrm{kg} \mathrm{ha}^{-1}\right)$ da parte aérea, sendo coletada plantas em $1 \mathrm{~m}^{2}$ em cada subparcela. A colheita foi realizada em 20/04/2014, avaliando-se 10 plantas ao acaso por subparcela as seguintes características: A altura da inserção da primeira vagem $(\mathrm{cm})$, a altura da planta $(\mathrm{cm})$, o número de vagens por planta, o número de grãos por vagem. Também foram avaliados o estande final, com a contagem do número de plantas contidos em 2,0 $\mathrm{m}$ de fileira de cada subparcela e calculado por hectare, a massa de 100 grãos, determinando-se através da coleta ao acaso e da pesagem de oito amostras de 100 grãos de cada subparcela (13\% umidade) e a produtividade de grãos, a partir da colheita das duas linhas centrais de cada subparcela.

No plantio do milho foi utilizado a cultivar DKB $390 \mathrm{RR}^{\circledR}$ que foi semeado, na densidade de 3 sementes por metro de sulco e, espaçamento de 0,50 m entrelinhas, correspondendo aproximadamente 60.000 sementes $\mathrm{ha}^{-1}$. No momento da emissão do pendão (flor masculina) das plantas de milho (30/01/2014) foi realizada a amostragem de folhas para ser determinada a produção de matéria seca (kg $\mathrm{ha}^{-1}$ ) da parte aérea, sendo coletada plantas em $1 \mathrm{~m}^{2}$ em cada subparcela. A colheita do milho foi realizada em 20/04/2014, avaliando-se 10 plantas ao acaso por subparcela as seguintes características: O diâmetro do colmo, a altura de plantas e da inserção da primeira espiga. Também foram avaliados o estande final e o número de espiga por planta, onde foram consideradas as 2 linhas centrais, dentro de cada subparcela, o número de grãos por espiga determinando-se em 10 espigas escolhidas aleatoriamente provenientes da área útil de cada subparcela, a massa de 100 grãos, onde foi avaliada através de quatro amostragens, de 100 grãos cada uma, em cada subparcela e a produtividade de grãos das plantas contidas na área útil de cada subparcela.

No plantio do sorgo sacarino foi utilizado a cultivar BRS 511 que foi semeado, na densidade de 8 sementes por metro de sulco e, espaçamento de 0,50 m entrelinhas, correspondendo aproximadamente 160.000 sementes $\mathrm{ha}^{-1}$. No florescimento das plantas de sorgo (21/02/2014) foi determinada a produção de matéria seca $\left(\mathrm{kg} \mathrm{ha}^{-1}\right)$ da parte aérea, sendo coletada plantas em $5 \mathrm{~m}$ linear em cada subparcela. A colheita do sorgo foi realizada em 25/04/2014, sendo avaliados: A altura de plantas, efetuadas em 10 plantas escolhidas aleatoriamente dentro da área útil de cada subparcela, o estande final, considerando as 2 linhas centrais, dentro de cada subparcela e a produção de matéria verde e seca: coletadas plantas em $5 \mathrm{~m}$ linear em cada subparcela.

No plantio do amendoim foi utilizado a cultivar IAC 503 que foi semeado na densidade de 10 sementes por metro de sulco e, espaçamento de 1,00 m entrelinhas, correspondendo aproximadamente 100.000 sementes $\mathrm{ha}^{-1}$. No florescimento pleno das plantas de amendoim (11/02/2014), foi determinada a produção de matéria seca $\left(\mathrm{kg} \mathrm{ha}^{-1}\right)$ da parte aérea, sendo coletada plantas em $1 \mathrm{~m}^{2}$ em cada subparcela. A colheita do amendoim foi realizada em 05/05/2014, avaliando-se 10 plantas ao acaso por subparcela as seguintes características: $\mathrm{O}$ número de vagens por planta, o número de grãos por vagem. Também foram avaliados o estande final com a contagem do número de plantas contidos em 10,0 m de fileira de cada subparcela e calculado por hectare, no momento da colheita, a massa de 100 grãos e a produtividade de grãos, a partir da colheita das duas linhas centrais de cada subparcela. 
A adubação verde foi feita através da associação de Crotalaria juncea (Crotalaria juncea), cultivar IAC KR1 e Labelabe (Dolichos lablab L.) foram semeadas, concomitantemente, no espaçamento 0,50 m, ajustando o número de sementes na linha de cada espécie, para 600.000 e 150.000 plantas ha ${ }^{-1}$, para crotalária e labelabe, respectivamente. No florescimento dos adubos verdes (31/03/2014) foi determinada a produção de matéria seca $\left(\mathrm{kg} \mathrm{ha}^{-1}\right)$ da parte aérea, onde foi coletado plantas em $1 \mathrm{~m}^{2}$ em cada subparcela.

Os resultados obtidos foram submetidos à análise de variância, e as médias foram comparadas pelo teste Tukey, a 5\% de probabilidade.

\section{RESULTADO E DISCUSSÃO}

Os dados diários referentes às temperaturas máxima, mínima e precipitação pluvial durante a condução do experimento, coletados na Estação Meteorológica da Unidade de Pesquisa e Desenvolvimento de Andradina-SP, estão contidos na (Figura 1). Pode-se verificar que as quantidades inferior a $450 \mathrm{~mm}$ de chuva, com a ocorrência de temperaturas muito elevadas e chuvas mal distribuídas.

Figura 1. Precipitação (-), temperaturas máxima (-) e mínima (—), registradas durante a condução dos experimentos, Andradina, SP, 2013/14.

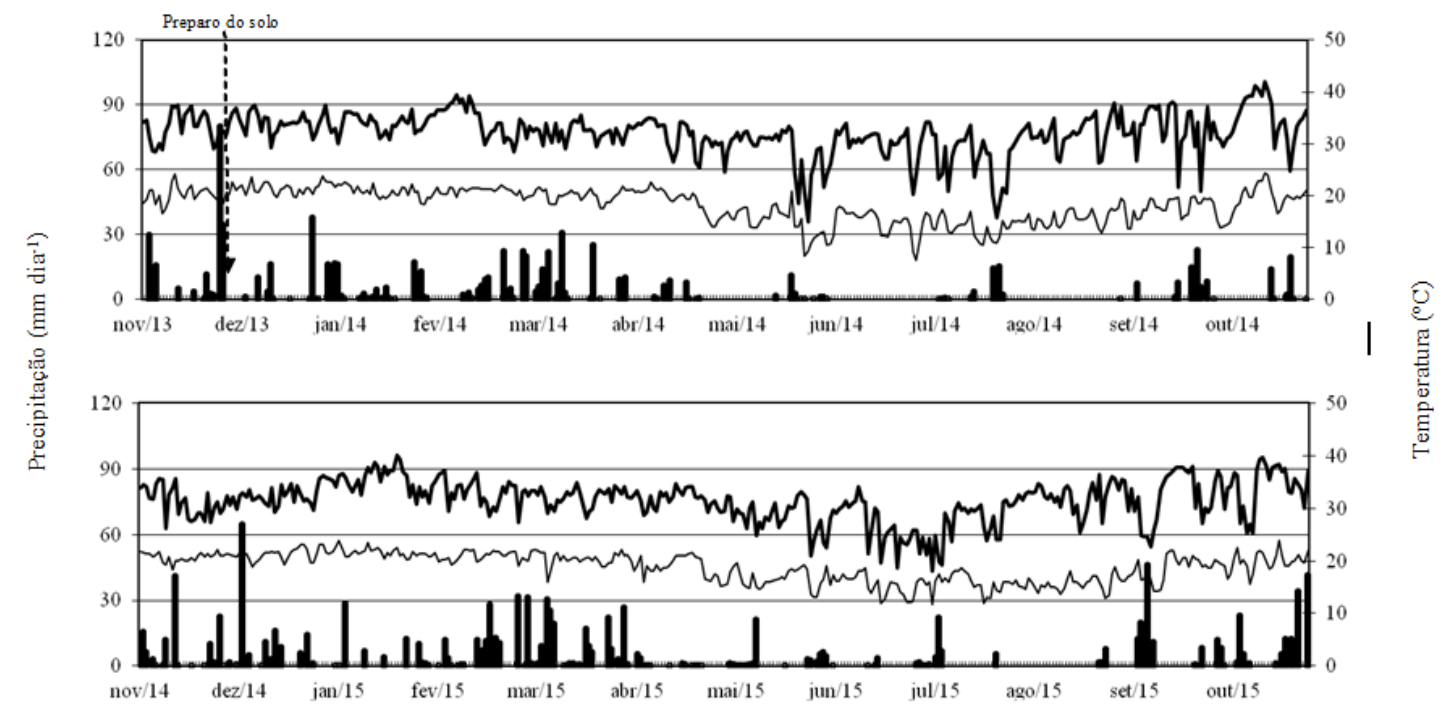

Assim pode-se verificar que a disponibilidade hídrica foi desfavorável para o crescimento e desenvolvimento das plantas de amendoim, milho e sorgo, e soja. Entre os meses de dezembro até fevereiro de 2014 foi registrada quantidades inferior a $450 \mathrm{~mm}$ de chuva, com a ocorrência de temperaturas muito elevadas e chuvas mal distribuídas. Sabe-se que a cultura do amendoim demanda pelo menos $600 \mathrm{~mm}$ de água durante o ciclo de desenvolvimento para obtenção de produções comerciais (GILLIER; SILVESTRE,1970). Para a cultura do milho e sorgo as quantidades requeridas são de 350 a 500 mm no verão (FANCELLI; DOURADO NETO, 2000; MAGALHÃES et al., 2000). Para a cultura da soja a necessidade total de água para obtenção do máximo rendimento, varia entre 450 a $800 \mathrm{~mm} /$ ciclo, dependendo das condições climáticas, do manejo da cultura e da duração do ciclo.

Por meio da Figura 1 pode-se verificar que a disponibilidade hídrica não foi favorável para o crescimento e desenvolvimento das plantas. Entre os meses de dezembro até maio foram registradas quantidades inferiores a $450 \mathrm{~mm}$ de chuva, aliado a vários dias com temperaturas superiores a $35^{\circ} \mathrm{C}$. Devese destacar ainda que o período compreendido entre 10/01/2014 e 28/02/2014 a quantidade de chuva acumulada foi inferior a $70 \mathrm{~mm}$ e em algumas ocasiões a temperatura máxima superou os $40^{\circ} \mathrm{C}$ (Figura 1), 
sendo que nesse período as plantas encontravam-se em fase de crescimento vegetativo e reprodução, comprometendo assim a produção de biomassa da parte aérea.

A produção de biomassa seca da parte aérea foi influenciada pelo manejo de solo e pelas culturas (Tabela 1). Constata-se que as maiores produções de massa seca vegetal foram obtidas no manejo de solo convencional e no preparo reduzido. Esse resultado difere de Bolonhezi (2007), onde a biomassa seca do amendoim IAC Tatu foi maior em plantio direto no palhiço da cana.

Para a produção de materia seca das culturas o maior destaque foi a associação de adubos verdes, produzindo $10190 \mathrm{~kg} \mathrm{ha}^{-1}$. Resultados semelhantes foram obtidos por Ambrosano et al. (2011), onde esses autores destacam a capacidade de produção de matéria seca da crotalária juncea. Em condição de pousio a produção de biomassa seca $\left(4632 \mathrm{~kg} \mathrm{ha}^{-1}\right)$ foi superior a relatada por Duarte Júnior; Coelho (2008), a provável justificativa pode estar relacionada as diferenças nas espécies da vegetação espontânea que desenvolveram nessa condição. Para a produção de materia seca do amendoim $\left(5078 \mathrm{~kg} \mathrm{ha}^{-1}\right)$ foi superior a observada por Ambrosano et al. (2011). Convém mencionar que para as condições desse experimento não houve diferenças estatísticas para produção de materia seca de amendoim e milho $\left(6723 \mathrm{~kg} \mathrm{ha}^{-1}\right)$. Para a produção de materia seca do sorgo $\left(9018 \mathrm{~kg} \mathrm{ha}^{-1}\right)$ foi estatisticamente semelhante a obtida pelos adubos verdes $\left(10190 \mathrm{~kg} \mathrm{ha}^{-1}\right)$; porém foi inferior à obtida por Mateus (2007). Evidencia se dessa forma que a restrição hídrica no período de crescimento vegetativo e reprodução influenciou de forma distinta as culturas utilizadas em rotação.

Tabela 1: Matéria seca da parte aérea $\left(\mathrm{kg} \mathrm{ha}^{-1}\right)$, no florescimento das culturas, em razão do manejo do solo e espécies vegetais em área de renovação de canavial. Andradina, SP, safra 2013/14.

\begin{tabular}{|c|c|c|c|}
\hline Manejo do solo & $\mathrm{kg} \mathrm{ha}^{-1}$ & Culturas & kg ha $^{-1}$ \\
\hline Convencional & $7157 a$ & Adubos verdes & $10190 \mathrm{a}$ \\
\hline Preparo reduzido & $6195 \mathrm{ab}$ & Amendoim & $5078 \mathrm{bc}$ \\
\hline \multirow[t]{4}{*}{ Plantio direto } & $5713 \mathrm{~b}$ & Milho & $6723 \mathrm{~b}$ \\
\hline & & Pousio & $4632 \mathrm{c}$ \\
\hline & & Soja & $2487 \mathrm{~d}$ \\
\hline & & Sorgo sacarino & $9018 \mathrm{a}$ \\
\hline Valor de F & $7,55^{* *}$ & Valor de $\mathbf{F}$ & $34,68^{* *}$ \\
\hline \multicolumn{2}{|c|}{ Valor de F - Manejo do solo x Culturas } & \multicolumn{2}{|c|}{$1,81^{\mathrm{ns}}$} \\
\hline \multicolumn{2}{|c|}{ CV $1(\%)$} & \multicolumn{2}{|c|}{20,63} \\
\hline \multicolumn{2}{|c|}{ CV $2(\%)$} & \multicolumn{2}{|c|}{26,66} \\
\hline
\end{tabular}

Valores seguidos de mesma letra nas colunas não diferem entre si por tukey a $5 \%{ }^{* *},{ }^{*} \mathrm{e}^{\mathrm{ns}}$, significativo a $1 \%$ e $5 \%$.

Para a soja na Tabela 2 estão apresentados os dados de altura e altura da inserção $1^{\circ}$ vagem e altura da planta de soja, que não foram afetados pelos sistemas de manejo de solo. No entanto, em todos os tratamentos a altura foi superior $65 \mathrm{~cm}$, bem como, a altura de inserção da $1^{\circ}$ vagem superior a $10 \mathrm{~cm}, \mathrm{o}$ que possibilitaria colheita mecanizada da cultivar de soja Valiosa RR, uma vez que os valores estavam acima dos padrões exigidos para tal operação (BONETTI, 1983).

Os resultados de estande final de plantas, número de vagens por planta, número de grãos por vagem, massa de 100 grãos e produtividade de grãos estão inseridos na Tabela 3. Constatou-se efeito de manejo de solo somente para estande final de plantas, sendo que no plantio direto houve maior valor.

A maior proteção e retenção de água no solo, devido a camada de palha, pode ter contribuído positivamente na germinação das sementes, e principalmente, no estabelecimento das plântulas de soja, proporcionando maior estande final.

Não houve uma relação entre as variáveis número total de vagens por planta e número de grãos por vagem da soja e os sistemas de manejo. Esses resultados corroboram aos obtidos por Santos; Reis 
(1991).

Com relação a massa de 100 grãos verifica-se que esta variável não foi influenciada pelo sistema de manejo, atingindo valor médio de 19,37 gramas. Mesmo como a melhor cobertura do solo nas áreas de manejo conservacionistas de solo, esperava-se uma manutenção maior do teor de água no solo que, consequentemente, propiciariam melhor enchimento de grãos, fato que pode ser comprovado pelos relatos de Bergamin et al. (1999) que relataram que déficit hídrico em estádio avançado da planta de soja refletirá em menor tamanho de grãos.

Quanto a produtividade de grãos não houve diferença estatística entre os tratamentos, mas o maior valor foi obtido no plantio direto. Tal resultado pode ser atribuído a maior população de plantas, decorrente de maior germinação e emergência de plântulas, e da massa de 100 grãos, decorrente da maior disponibilidade hídrica durante o processo de enchimento das vagens. Resultados semelhantes foram observados por Sidiras et al. (1983).

Tabela 2: Altura de planta e altura da inserção da $1^{\circ}$ vagem da soja, em razão do manejo do solo em área de renovação de canavial. Andradina, SP, safra 2013/14.

\begin{tabular}{ccc}
\hline \multirow{2}{*}{ Manejo do solo } & Altura de plantas & $\begin{array}{c}\text { Altura da inserção da 10 } \\
\text { vagem }^{\mathbf{0}}\end{array}$ \\
\cline { 2 - 3 } & plantas ha $^{-1}$ & espigas ha $^{-1}$ \\
\hline Convencional & 69,2 & 13,1 \\
Preparo reduzido & 68,3 & 14,1 \\
Plantio direto & 71,3 & 11,7 \\
\hline Valor de $\mathbf{F}$ & $0,19^{\text {ns }}$ & $0,44^{\text {ns }}$ \\
\hline CV $(\%)$ & 10,10 & 27,73 \\
\hline
\end{tabular}

Valores seguidos de mesma letra nas colunas não diferem entre si por tukey a $5 \%{ }^{* *},{ }^{*} \mathrm{e}^{\mathrm{ns}}$, significativo a $1 \%$ e $5 \%$ e, não significativo, respectivamente.

Tabela 3: Estande final de plantas, número de vagens, número de grãos por vagem, massa de 100 grãos e produtividade de grãos de soja, em razão do manejo do solo em área de renovação de canavial. Andradina, SP, safra 2013/14.

\begin{tabular}{cccccc}
\hline & Estande & $\begin{array}{c}\text { Número de } \\
\text { vagens }\end{array}$ & $\begin{array}{c}\text { Número } \\
\text { de grãos } \\
\text { por } \\
\text { vanejo do solo }\end{array}$ & $\begin{array}{c}\text { Massa de } \\
\mathbf{1 0 0} \text { grãos }\end{array}$ & $\begin{array}{c}\text { Produtividade de } \\
\text { grãos }\end{array}$ \\
\cline { 2 - 6 } & plantas ha $^{-1}$ & $\begin{array}{c}\text { Vagens }^{-1} \\
\text { planta }^{-1}\end{array}$ & & $\mathrm{~g}$ & $\mathrm{~kg} \mathrm{ha}^{-1}$ \\
\hline Convencional & 192776 & 49,1 & 1,2 & 18,3 & 1078 \\
Preparo reduzido & 259442 & 41,1 & 1,2 & 18,9 & 1076 \\
Plantio direto & 306664 & 41,9 & 1,5 & 20,9 & 1613 \\
\hline Valor de F & $7,45^{*}$ & $0,53^{\mathrm{ns}}$ & $2,26^{\mathrm{ns}}$ & $2,50^{\mathrm{ns}}$ & $2,12^{\mathrm{ns}}$ \\
\hline CV (\%) & 16,57 & 27,28 & 18,70 & 8,84 & 33,91 \\
\hline
\end{tabular}

Valores seguidos de mesma letra nas colunas não diferem entre si por tukey a $5 \%$.**, * e ns, significativo a 1\% e 5\% e, não significativo, respectivamente.

Para o milho na Tabela 4 estão os resultados de altura de plantas, altura da inserção da espiga e diâmetro de colmo do milho em função do sistema de manejo do solo. Constata-se que não houve efeito significativo dos fatores aplicados para todos as variáveis. De acordo com Silva (2000), a altura da inserção da primeira espiga está diretamente relacionada com a altura de plantas, ou seja, plantas de maior altura resultam em maiores alturas de inserção da espiga, o que pode estar relacionado a fatores genéticos. 
Os resultados de estande, índice de espiga, número de grãos por espiga, massa de 100 grãos e produtividade de grãos de milho encontram-se na Tabela 5. Constata-se que, com exceção ao estande de plantas, nenhuma variável foi afetada pelos fatores.

Para estande de plantas verificou-se que o plantio direto apresentou maior valor em relação ao preparo reduzido e convencional, observando média de 68888 plantas ha ${ }^{-1}$. A maior proteção e retenção de água no solo, devido a camada de palha, pode ter contribuído positivamente na germinação das sementes, e no estabelecimento das plântulas de milho, proporcionando adequado estande final neste sistema.

Comportamento inverso ao estande de plantas foi constatado para índice de espiga, ou seja, não houve efeito dos sistemas de cultivo, obtendo índice de espiga médio de 0,23. Ressaltasse que este valor é muito baixo frente aos comumente obtidos para a cultura do milho. Tal fato pode ser atribuído a forte seca ocorrida e as elevadas temperaturas diurnas e noturnas. Freddi et al. (2007) encontraram diferenças significativas na produtividade do milho em solos compactados devido a restrições no fornecimento de água no estádio de florescimento. Vale destacar que compactação do solo pode interferir na produtividade do milho, mesmo em condições de fornecimento de água com uso de irrigação (FREDDI et al., 2009).

Com relação ao número de grãos por espiga também não foi influenciado pelos sistemas de manejo de solo, os valores alcançados no presente trabalho estão muito aquém dos obtidos em condições normais de precipitação e temperaturas adequadas, ficando na média com 262 grãos por espiga, em todos os sistemas.

A massa de 100 grãos não foi influenciada pelo sistema de manejo, sendo o valor médio obtido de 26,6 gramas.

Com relação à produtividade de grãos constata-se que o fator manejo de solo não exerceu influência significativa nesta variável. A não resposta da produtividade de grãos ao sistema de menejo de solo é consequência, principalmente, dos resultados verificados para índice de espiga, número de grãos por espiga e massa de 100 grãos, uma vez que, sendo estes os componentes da produção, e não foram alterados pelos tratamentos, por conseguinte esses resultados refletiram na produtividade de grãos.

De modo geral, fica difícil concatenar os resultados obtidos face a grande influência climática na cultura, o que tornou a água um elemento limitante ao desenvolvimento das plantas de milho. Para a cultura do milho e sorgo as quantidades requeridas são de 350 a $500 \mathrm{~mm}$ no verão (FANCELLI; DOURADO NETO, 2000; MAGALHÃES et al., 2000). Mateus (2007) obteve produtividade próxima de $9000 \mathrm{~kg} \mathrm{ha}^{-1}$, sendo registrado quantidade de chuva próximas a $600 \mathrm{~mm}$. Dessa forma os $450 \mathrm{~mm}$ registrados nas condições desse experimento deveriam ser suficientes para garantir produtividades razoáveis. Todavia não foi o que aconteceu, pois a frequência de chuva e a demanda evapotranspirativa impactaram de forma mais significativa na produtividade do milho. Vilela; Büll (1999) encontraram diferenças significativas na produção de massa de matéria seca de plantas de milho submetidas à deficiência hídrica na fase reprodutiva. Embora esses autores tenham trabalhado em condição de casa de vegetação, pode ser utilizada para justificar a baixa produtividade obtidas nesse experimento $\left(700 \mathrm{~kg} \mathrm{ha}^{-1}\right)$, sendo que o período compreendido entre 10/01/2014 e 28/02/2014 a quantidade de chuva acumulada foi inferior a $70 \mathrm{~mm}$ e em algumas ocasiões a temperatura máxima superou os $40^{\circ} \mathrm{C}$ (Figura 1), coincidindo com o final da fase vegetativa e o início da fase reprodutiva. Nesse experimento, mesmo com a grande quantidade de palha no sistema plantio direto, não foi suficiente para assegurar a manutenção da umidade do solo e garantir as boas produtividades do milho. 
Tabela 4: Altura de planta, altura da inserção da espiga e diâmetro do colmo do milho, em razão do manejo do solo em área de renovação de canavial. Andradina, SP, safra 2013/14.

\begin{tabular}{cccc}
\hline Manejo do solo $(\mathbf{P})$ & $\begin{array}{c}\text { Altura de } \\
\text { plantas }\end{array}$ & $\begin{array}{c}\text { Altura da } \\
\text { inserção da } \\
\text { espiga }\end{array}$ & $\begin{array}{c}\text { Diâmetro do } \\
\text { colmo }\end{array}$ \\
\cline { 2 - 4 } & plantas ha $^{-1}$ & espigas ha $^{-1}$ \\
\hline Convencional & 162,9 & 94,6 & 21,0 \\
Preparo reduzido & 186,1 & 108,8 & 22,5 \\
Plantio direto & 178,6 & 101,1 & 21,4 \\
\hline Valor de $\mathbf{F}$ & $3,99^{\text {ns }}$ & $3,66^{\text {ns }}$ & $1,15^{\text {ns }}$ \\
\hline CV $(\%)$ & 6,75 & 7,33 & 6,63 \\
\hline
\end{tabular}

Valores seguidos de mesma letra nas colunas não diferem entre si por tukey a $5 \%$.**, * e ns, significativo a $1 \%$ e $5 \%$ e, não significativo, respectivamente.

Tabela 5: Estande final de plantas, número de espigas, índice de espigas, massa de 100 grãos e produtividade de grãos de milho, em razão do manejo do solo em área de renovação de canavial. Andradina, SP, safra 2013/14.

\begin{tabular}{cccccc}
\hline Manejo do solo & Estande & $\begin{array}{c}\text { Índice de } \\
\text { Espigas }\end{array}$ & $\begin{array}{c}\text { Número } \\
\text { de grãos } \\
\text { por espiga }\end{array}$ & $\begin{array}{c}\text { Massa de } \\
\text { 100 grãos }\end{array}$ & $\begin{array}{c}\text { Produtividade de } \\
\text { grãos }\end{array}$ \\
\cline { 2 - 5 } & plantas ha $^{-1}$ & & & $\mathrm{~g}$ & $\mathrm{~kg} \mathrm{ha}^{-1}$ \\
\hline Convencional & $54444 \mathrm{~b}$ & 0,28 & 239 & 25,8 & 616 \\
Preparo reduzido & $51111 \mathrm{~b}$ & 0,14 & 269 & 27,1 & 298 \\
Plantio direto & $68888 \mathrm{a}$ & 0,27 & 278 & 26,9 & 1188 \\
\hline Valor de F & $11,63^{* *}$ & $3,13^{\mathrm{ns}}$ & $0,34^{\mathrm{ns}}$ & $0,06^{\mathrm{ns}}$ & $1,43^{\mathrm{ns}}$ \\
\hline CV (\%) & 8,13 & 40,67 & 26,92 & 22,01 & 107,67 \\
\hline
\end{tabular}

Valores seguidos de mesma letra nas colunas não diferem entre si por tukey a $5 \%$.**, * e ns, significativo a $1 \%$ e $5 \%$ e, não significativo, respectivamente.

Para o sorgo sacarino a partir do florescimento pleno (87 dias após o plantio - DAP) avaliou-se semanalmente a porcentagem de biomassa seca da parte aérea e o teor de Brix do caldo das plantas de sorgo sacarino (Tabela 6).

Ao final do período de coletas (143 DAP) avaliaram-se estande final, produção de biomassa fresca e seca da parte aérea. Para a \% MS da planta, bem como o brix do caldo não houve efeito dos manejos do solo e da interação manejo do solo e época de amostragem. Entretanto, essas duas variáveis foram influenciadas pelo fator época de amostragem.

Para a porcentagem de biomassa seca da parte aérea constatou-se ajuste quadrático para época de amostragem $\left(y=-0,0021 x^{2}+0,3679 x+19,581, R^{2}=0,76^{* * *}\right)$, sendo que os valores oscilaram entre $19,6 \%$ no florescimento pleno e $33,6 \%$ aos 56 dias após.

Com relação a produção de biomassa fresca e seca da parte aérea e estande final de plantas não verificou efeitos dos manejos de solo adotados. As médias obtidas, nos diferentes tratamentos, foram de 61683 e $20231 \mathrm{~kg} \mathrm{ha}^{-1}$ para a produção de biomassa fresca e seca da parte aérea, respectivamente, bem abaixo da média de $46360 \mathrm{~kg} \mathrm{ha}^{-1}$ obtidos por Parrella et al. (2010). Destaca que semelhante às outras culturas utilizadas em rotação o défice hídrico foi prejudicial ao bom desenvolvimento do sorgo sacarino. 
Tabela 6: Produção de massa de matéria verde e seca, estande final de plantas e teor de Brix do caldo de sorgo sacarino, em razão do manejo do solo em área de renovação de canavial. Andradina, SP, safra $2013 / 14$

\begin{tabular}{ccccc}
\hline \multirow{2}{*}{ Manejo do solo } & $\begin{array}{c}\text { Matéria } \\
\text { Verde }\end{array}$ & $\begin{array}{c}\text { Matéria } \\
\text { Seca }\end{array}$ & Estande & ${ }^{\mathbf{o}}$ Brix \\
\cline { 2 - 5 } & \multicolumn{2}{c}{$\mathrm{kg} \mathrm{ha}^{-1}$} & & \\
\hline Convencional & 62783 & 20991 & 150000 & 22,7 \\
Preparo reduzido & 58075 & 18321 & 175000 & 21,6 \\
Plantio direto & 64192 & 21383 & 158333 & 22,6 \\
\hline Valor de F & $0,25^{\text {ns }}$ & $0,69^{\text {ns }}$ & $2,04^{\text {ns }}$ & $1,36^{\text {ns }}$ \\
\hline CV (\%) & 20,76 & 19,73 & 11,06 & 4,79 \\
\hline
\end{tabular}

Valores seguidos de mesma letra nas colunas não diferem entre si por tukey a $5 \%$.**, * e ns, significativo a $1 \%$ e $5 \%$ e, não significativo, respectivamente.

O estande final de plantas foi de 161110 plantas ha $^{-1}$, valor próximo ao almejado no plantio (180000 plantas $\mathrm{ha}^{-1}$ ). Pereira Filho et al. (2013) encontraram aumento linear de produtividade do sorgo sacarino com o aumento da população de plantas e obtiveram máxima produtividade com a população de 175000 plantas $\mathrm{ha}^{-1}$; dessa forma, a população de plantas não interferiu na produtividade do sorgo, mas sim o déficit hídrico durante o desenvolvimento da cultura.

Figura 2. Porcentagem de matéria seca da planta de sorgo sacarino após florescimento (87 DAP). Andradina, SP, 2013/14.

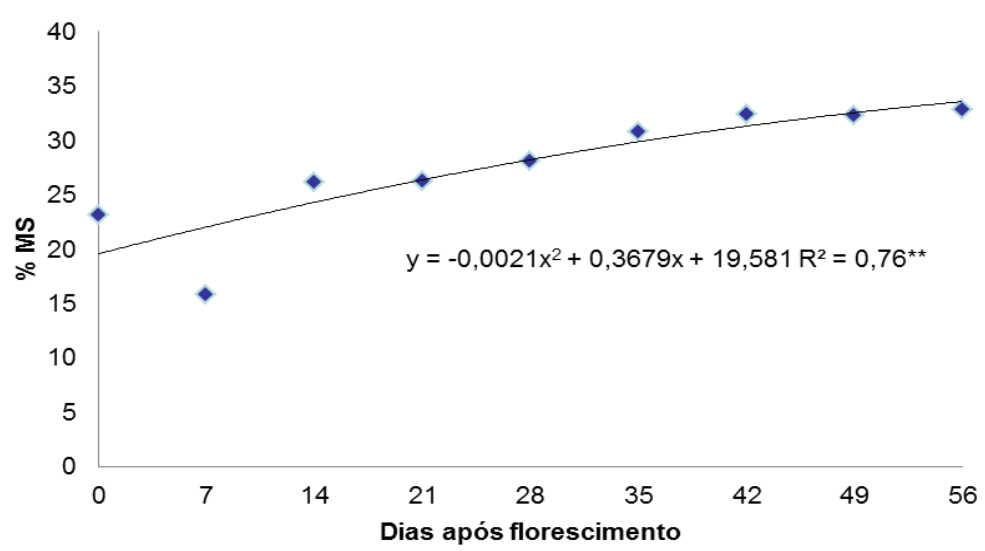

Para a cultura do amendoim constata-se que não houve efeito dos sistemas de manejo do solo para as variáveis estande de plantas, número de vagens por planta, número de grãos por vagem (Tabela 7), além de produtividade de grãos e rendimento de grãos (Tabela 8). Já para massa de 100 grãos e produção de vagens houve efeito dos tratamentos.

Para massa de 100 grãos constatou-se que no plantio direto houve maior peso em relação ao preparo reduzido e convencional, porém não proporcionou maiores rendimentos de grãos. A produção de vagens do amendoim foi maior no sistema de cultivo convencional em relação ao sistema plantio direto obtendo valores de 2170 e $1310 \mathrm{~kg} \mathrm{ha}^{-1}$, respectivamente (Tabela 8). Esses resultados assemelham-se aos obtidos por Soratto; Crusciol (2007), onde, o cultivo do amendoim em plantio direto na palha de braquiária, proporcionou a produção abaixo de $1800 \mathrm{~kg} \mathrm{ha}^{-1}$. Entretanto diferem dos obtidos por Bolonhezi et al. (2007) onde não houve diferenças estatísticas entre o sistema convencional, preparo reduzido e plantio direto. Destaca que esses mesmos autores obtiveram em algumas situações produtividade de vagens superiores a $5000 \mathrm{~kg} \mathrm{ha}^{-1}$, muito superior as obtidas nas condições desse experimento. A população final próxima de 60000 plantas ha $^{-1}$ foi suficiente para proporcionar produtividades acima de $4500 \mathrm{~kg} \mathrm{ha}^{-1}$ na cultivar IAC RUNNER 886 (ROMANINI JÚNIOR, 2007). Descarta a possibilidade de deficiências 
nutricionais terem comprometido a produção, pois os valores de macronutrientes foram semelhantes ao que se tem relatado na literatura para obtenção de boas produtividades de vagem ha ${ }^{-1}$ (GASCHO; DAVIS, 1995; BOLONHEZI, 2007; SORATTO; CRUSCIOL, 2007).

Assim destaca-se que o fator principal da baixa produtividade do amendoim, para essas condições experimentais, foi relacionada a baixa disponibilidade hídrica durante seu ciclo. O amendoim é considerado uma planta que possui a capacidade de tolerar deficiências hídricas sem comprometer a produtividade. Isso se deve a algumas características, como sistema radicular mais vigoroso e melhor controle estomático, sendo que algumas cultivares apresentam maior tolerância ao estresse hídrico (AZEVEDO NETO et al., 2010

Vale ressaltar que se esperava que a presença do palhiço da cana na superfície do solo poderia ter aumentado a capacidade de armazenamento de água da chuva, favorecendo a absorção de água e nutrientes pelas plantas de amendoim. Bolonhezi et al. (2007) relatam que após 10 dias sem chuvas superiores a $5 \mathrm{~mm}$, o conteúdo de água na camada de 0,00-0,12 $\mathrm{m}$ foi $16 \%$ superior no plantio direto quando comparado ao sistema convencional.

Tabela 7: Estande final de plantas, número de vagens por planta, número de grãos por vagem e massa de 100 grãos de amendoim, em razão do manejo do solo em área de renovação de canavial. Andradina, SP, safra 2013/14.

\begin{tabular}{|c|c|c|c|c|}
\hline \multirow[t]{2}{*}{ Manejo do solo } & Estande & $\begin{array}{l}\text { Número de } \\
\text { vagens }\end{array}$ & $\begin{array}{c}\text { Número de } \\
\text { grãos por } \\
\text { vagem }\end{array}$ & $\begin{array}{l}\text { Massa de } \\
100 \text { grãos }\end{array}$ \\
\hline & plantas $\mathrm{ha}^{-1}$ & $\begin{array}{l}\text { Vagens } \\
\text { planta }^{-1}\end{array}$ & & $\mathrm{~g}$ \\
\hline Convencional & 68333 & 35,5 & 1,5 & $60,8 \mathrm{~b}$ \\
\hline Preparo reduzido & 65277 & 34,6 & 1,4 & $60,1 \mathrm{~b}$ \\
\hline Plantio direto & 61666 & 23,0 & 1,4 & $72,4 \mathrm{a}$ \\
\hline Valor de F & $0,57^{\mathrm{ns}}$ & $1,35^{\mathrm{ns}}$ & $0,29^{\mathrm{ns}}$ & $8,88^{*}$ \\
\hline $\mathrm{CV}(\%)$ & 13,63 & 38,69 & 14,81 & 7,19 \\
\hline
\end{tabular}

Valores seguidos de mesma letra nas colunas não diferem entre si por tukey a $5 \%$.**, * e ns, significativo a $1 \%$ e $5 \%$ e, não significativo, respectivamente.

Além disso, a maior proteção do solo com a palha pode ter diminuído a oscilação e a ocorrência de altas temperaturas no solo (VOSS; SIDIRAS, 1985; MOROTE et al., 1990), favorecendo melhor exploração do volume do solo, uma vez que, o crescimento das raízes do amendoim está relacionado com a temperatura e umidade do solo. Grichar; Smith (1991), demonstram que a viabilidade da produção de amendoim em sistemas conservacionistas de manejo do solo depende do cultivar e do ano de condução.

Tabela 8: Produção de vagens, grãos e índice de rendimento de grãos de amendoim, em razão do manejo do solo em área de renovação de canavial. Andradina, SP, safra 2013/14.

\begin{tabular}{cccc}
\hline Manejo do solo & $\begin{array}{c}\text { Produção de } \\
\text { vagens }\end{array}$ & $\begin{array}{c}\text { Produtividade de } \\
\text { grãos }\end{array}$ & $\begin{array}{c}\text { Rendimento de } \\
\text { grãos }\end{array}$ \\
\cline { 2 - 4 } & $\mathrm{kg} \mathrm{ha}^{-1}$ & $\mathrm{~kg} \mathrm{ha}^{-1}$ & $\%$ \\
\hline Convencional & $2170 \mathrm{a}$ & 1502 & 69,0 \\
Preparo reduzido & $1903 \mathrm{ab}$ & 1311 & 69,0 \\
Plantio direto & $1310 \mathrm{~b}$ & 918 & 67,3 \\
\hline Valor de F & $9,85^{*}$ & $3,22^{\text {ns }}$ & $0,02^{\text {ns }}$ \\
\hline CV $(\%)$ & 15,63 & 26,66 & 19,92 \\
\hline
\end{tabular}

Valores seguidos de mesma letra nas colunas não diferem entre si por tukey a $5 \%$.**, * e ns, significativo a $1 \%$ e $5 \%$ e, não significativo, respectivamente. 
Para a instalação do tratamento adubos verdes não houve efeito dos modos de manejo de solo sobre a produção de massa seca da crotalária e labelabe e Total (Tabela 9). A média de produção de fitomassa seca da crotalária e labelabe e Total foi de 8898, 1292 e $10190 \mathrm{~kg} \mathrm{ha}^{-1}$, respectivamente. Diante desses valores verifica-se que a crotalária representou $87,3 \%$ e o labelabe $12,7 \%$ do total produzido de massa seca dos adubos verdes. Destaca-se que mesmo em condição de associação de leguminosas, como ocorreu nesse experimento, a produtividade de biomassa seca da Crotalaria juncea L. foi de $8898 \mathrm{~kg} \mathrm{ha}^{-1}$, sendo esse resultado muito semelhante aos $9300 \mathrm{~kg} \mathrm{ha}^{-1}$ obtidos por Ambrosano et al. (2011) para as condições de Piracicaba em cultivo solteiro. Dessa forma conclui que a associação da crotalária com o labelabe não influenciou a produtividade da crotalária. Tal fato pode ser explicado pelo crescimento da Crotalaria juncea L. ser do tipo ereto e as plantas atingirem alturas superiores a 3 metros, ao passo que o labelabe apresenta hábito de crescimento trepador, atingindo altura de no máximo 1 metro. Aliado ao hábito de crescimento e porte da planta a crotalaria é uma das leguminosas de mais rápido crescimento inicial o que a favoreceu ainda mais na competição interespecífica.

Pode se concluir que a Crotalaria juncea L. produz praticamente sete vezes mais em relação ao labelabe, quando ocorre o cultivo associado dessas duas leguminosas. Porém deve-se destacar que a associação de adubos verdes, nessas condições experimentais, foi o tratamento que teve a menor susceptibilidade ao severo déficit hídrico ocorrido nos meses de janeiro e fevereiro de 2014, tendo em vista que a produtividade de biomassa seca foi muito semelhante ao que normalmente é relatado na literatura, mesmo em condições experimentais mais favoráveis ao desenvolvimento dos adubos verdes (DUARTE JÚNIOR; COELHO, 2008; AMBROSANO et al., 2009; AMBROSANO et al., 2011).

No noroeste paulista é comum ocorrer a combinação de períodos de "veranicos" no verão, solos com baixa capacidade de reter água (arenosos) e grande demanda evapotranspirativa. Nessas condições há viabilidade de utilização de adubos verdes, em qualquer tipo de manejo do solo, porém deve-se destacar o plantio direto, principalmente por não apresentar diferenças significativas no desenvolvimento vegetativo dessas espécies, mesmo em condições desfavoráveis como compactação do solo e déficit hídrico. Vale ressaltar que no plantio direto, ocorre a aliança de melhoria nas qualidades físicas, químicas e biológicas do solo à mitigação nos custos de produção. A grande rusticidade dos adubos verdes é destacada por Cárceres; Alcarde, (1995), principalmente a espécie Crotalaria juncea L., o que torna essa espécie muito utilizada em áreas de reforma de canaviais; essa situação apresenta alguns benefícios que vão além da prática da adubação verde e rotação de culturas.

Tabela 9: Produção de massa de matéria seca de Crotalária, Labelabe e total, em razão do manejo do solo em área de renovação de canavial. Andradina, SP, safra 2013/14.

\begin{tabular}{|c|c|c|c|}
\hline \multirow{2}{*}{ Manejo do solo } & Crotalária & Labelabe & Total \\
\hline & \multicolumn{3}{|c|}{ 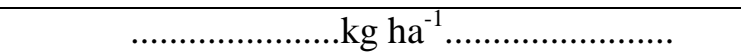 } \\
\hline Convencional & 9114 & 1146 & 10259 \\
\hline Preparo reduzido & 8876 & 1533 & 10409 \\
\hline Plantio direto & 8703 & 1198 & 9901 \\
\hline Valor de F & $0,07^{\mathrm{ns}}$ & $2,25^{\mathrm{ns}}$ & $0,12^{\mathrm{ns}}$ \\
\hline CV (\%) & 17,36 & 21,68 & 15,06 \\
\hline
\end{tabular}

Valores seguidos de mesma letra nas colunas não diferem entre si por tukey a $5 \%$.** * e ns, significativo a $1 \%$ e $5 \%$ e, não significativo, respectivamente.

\section{CONCLUSÃO}

A baixa disponibilidade de chuvas durante o período de crescimento vegetativo e reprodutivo das culturas de rotação influenciaram negativamente a produtividade do amendoim, milho e soja, o plantio direto propiciou maior estande de plantas no milho. 
Os benefícios da adubação verde não foram evidenciados nessa condição experimental. A maior produtividade da cana ocorreu no tratamento soja.

\section{AGRADECIMENTOS}

À Fundação de Apoio à Pesquisa do Estado de São Paulo pelo financiamento da pesquisa (Processo FAPESP no 2012/50673-9).

\section{REFERÊNCIAS}

ALLEONI, L. R. F.; BEAUCLAIR, E. G. F. Cana-de-açúcar cultivada após milho e amendoim, com diferentes doses de adubo. Scientia Agrícola, [S.1], v. 53, n. 3, p.409-415, 1995.

AMERICAN SOCIETY OF AGRICULTURAL ENGINEERS (ASAE). Terminology and definitions for agricultural tillage implements. In: ASAE standars 1997: standars engineering practices data. St. Joseph, 1997. p. 254-275.

AMBROSANO, E. J. A. et al. Utilization of nitrogen from green manure and mineral fertilizer by sugarcane. Scientia Agrícola, [S.1], v.62, p. 534-542, 2005.

AMBrosanO, E. J. A. et al. Adubos Verdes e Amendoins Cultivados em Rotação com Cana-deaçúcar. Cadernos de Agroecologia, [S.1], v. 4, n. 1. 2009.

AMBROSANO, E. J. A. et al. Produtividade da cana de açúcar após o cultivo de leguminosas. Bragantia, [S.1], v.70, n.4, p. 810-818, 2011.

AMBROSANO, E. J. et al. Desempenho de adubos verdes e da primeira soqueira de cana-de açúcar cultivados consorciadamente. Revista Brasileira de Agroecologia, [S.L.], V. 8, N. 3, Dez. 2013.

AZEVEDO NETO, A. D. et al. Physiological and biochemical responses of peanut genotypes to water deficit. Journal Of Plant Interactions, [s.1.], v. 5, n. 1, p.1-10, mar. 2010.

AYALA,I. A. C. et al. Caña de Azúcar: Paradigma de Sostenibilidad. INICA, Instituto de Investigación de la Caña de Azúcar, Cuba, 2003. 169 p.

BAQUERO, J. E. et al. Soil physical properties and sugarcane root growth in a red oxiso. Revista Brasileira de Ciência do Solo, [S.1.], v. 36, n. 1, p.63-70, fev. 2012.

BERGAMIN, M. et al. Ecofisiologia da soja. Ecofisiologia de Cultivos Anuais: trigo, milho, soja, arroz e mandioca. São Paulo: Nobel, p. 73-90, 1999.

BOLONHEZI, D. Sistemas de manejo conservacionista do solo para cultivares de amendoim em sucessão à cana crua e pastagens. 2007, 158 f. Tese (Doutorado em Produção Vegetal) -Faculdade de Ciências Agrárias e Veterinárias, Jaboticabal, 2007.

BONETTI, L. P. Cultivares e seu melhoramento genético. In: VERNETTI, FJ Soja- genética e melhoramento. Campina. Fundação Cargill, p. 741-794, 1983

CACERES, N. T.; ALCARDE, J. C. Adubação verde com leguminosas em rotação com a cana-de-açúcar (Saccharum spp.) Revista STAB, [s.1], v.13, n.5, p.16- 20,1995.

CANASAT. Mapeamento da cana via imagens de satélite de observação da terra.Disponivel em: <http://www.dsr.inpe.br/canasat/> .Acesso em: 04 nov,2016. 
CASAGRANDI, D.V. Preparo mínimo de solos argisolos para a cultura de cana-deaçúcar. Álcool e Açúcar, São Paulo, v.8, n.40, p-30-3, 1988.

CHEN, G.; WEIL, R. R.. Root growth and yield of maize as affected by soil compaction and cover crops. Soil and Tillage Research, [s.1.], v. 117, p.17-27, dez. 2011.

CONDE, A.J. ; DONZELLI, J.L. Manejo conservacionista do solo para áreas de colheita mecanizada de cana queimada e sem queimar. VII Seminário Copersucar de Tecnologia Agronômica, [s.l.], p.193-205, 1997.

DERPSCH, R. et al. Controle da erosão no Paraná, Brasil: Sistemas de cobertura do solo, plantio direto e prepare conservacionista do solo. GTZ e IAPAR, 1991. 272 p.

DUARTE JÚNIOR, J. B.; COELHO, F. C. Adubos verdes e seus efeitos no rendimento da cana-de-açúcar em sistema de plantio direto. Bragantia, Campinas, v. 67, n. 3, p.723-732, 2008.

EMBRAPA - Empresa Brasileira de Pesquisa Agropecuária. Sistema brasileiro de classificação dos solos. Brasília, DF: EMBRAPA, 2006. 306 p.

FANCELLI, A. L.; DOURADO NETO, D. Produção de milho. Guaíba: Agropecuária, 2000.360p.

FEHR, W. R. et al. Stage of development descriptions for soybean, Glycine max (L.) Merrill. Crop Science, [s.1], v.11, p.929-931, 1971.

FREDDI, O. S. et al. Compactação do solo no crescimento radicular e produtividade da cultura do milho.

Revista Brasileira de Ciência do Solo, Viçosa, v. 1, n. 31, p.627-636, abr. 2007.

FREDDI, O. S. et al. Compactação do solo e produção de cultivares de milho em latossolo vermelho. Revista Brasileira de Ciência do Solo, Viçosa, v. 1, n. 33, p.805-818, abr. 2009.

GARCIA, R. A. et al. Potassium cycling in a corn-brachiaria cropping system. European Journal of Agronomy, [s.1.], v. 28, n. 4, p.579-585, maio 2008. Elsevier BV.

GASCHO, G.; DAVIS, J.G. Soil fertility and plant nutrition. In: PATEE, H.E.; STALKER, H.T. (Ed.). Advances in Peanut Science. Stillwater: American Peanut Research and Education Society, p.383-419, 1995.

GILLIER, P.; SILVESTRE, P. El cacahuete o maní. Madrid: Editorial Blume, 1970. 281p.

GRICHAR, W. J.; SMITH, O. D. Effects of tillage systems on Southern blight and pod yield of five runner peanut genotypes. Peanut Science, v.18, p.144-147, 1991.

MAGALHÃES, P.C.; DURAES, F.O.M.; SCHAFFERT, R.E. Fisiologia da planta de sorgo. Sete Lagoas: EMBRAPA, 2000. 46p. (Circular Técnica, 3)

MAIA, J. L. T.; RIBEIRO, R. Cultivo contínuo da cana-de-açúcar e modificações químicas de um Arissolo Amarelo fragipânico. Pesquisa Agropecuária Brasileira, v.39, n.11, p.1127-1132, 2004.

MASCARENHAS, H. A. A. et al. Efeito residual de leguminosas sobre o rendimento físico e econômico da cana-planta. Campinas, 1994, 15 p. (Boletim Científico n.o 32).

MAGALHÃES, P.C.; DURAES, F.O.M.; SCHAFFERT, R.E. Fisiologia da planta de sorgo. Sete Lagoas: EMBRAPA, 2000. 46p. (Circular Técnica, 3) 
MATEUS, G. P. Doses de nitrogênio na cultura do milho e do sorgo em consórcio com forrageiras. 2007. Dissertação (Mestrado em Agronomia / Agricultura) - Faculdade de Ciências Agronômicas, Universidade Estadual Paulista, Botucatu, 2007.

MUTTON, M. A. Efeitos de diferentes sistemas de preparo do solo na cultura da cana-de-açúcar (Sccharum spp. var. Na 5679).1983. 155 f. Dissertação (Mestrado em Ciências) - Faculdade de Ciências Agrárias e Veterinários, Jaboticabal, 1983.

PARRELLA, R. A. C. et al. Desempenho de cultivares de sorgo sacarino em diferentes ambientes visando a produção de etanol. In: XXVIII CONGRESSO NACIONAL DE MILHO E SORGO, 28, 2010, Goiania. Anais... . Goiania: Associação Brasileira de Milho e Sorgo. 2010. p. 2858 - 2866.

PEREIRA, F.A.R.; VELINI, E.D. Sistemas de cultivo no cerrado e dinâmica de populações de plantas daninhas. Planta Daninha, [s.1.], v.21, n.3, p. 355-363, 2003.

PEREIRA FILHO, I. A. et al. Avaliação de cultivares de sorgo sacarino [Sorghum bicolor (L.) Moench] em diferentes densidades de semeadura visando a características importantes na produção de etanol. Revista Brasileira de Milho e Sorgo, Sete Lagoas, v. 12, n. 2, p.118-127, set. 2013.

RAIJ, B. van et al. Recomendações de adubação e calagem para o estado de São Paulo. Campinas, Instituto Agronômico \& Fundação IAC, 1997. 285 p. (Boletim Técnico, 100).

SANTIAGO, A. A.; ROSETTO, R. Árvore do conhecimento. Cana de açúcar. AGEITEC (Agência Embrapa de Informações Tecnológica). Disponível em: http://www.agencia.cnptia.embrapa.br/gestor/cana-de acucar/arvore/CONTAG01_84_22122006154841.html> Acesso em: 24/02/2014.

SANTOS, H. P.; REIS, E. M. Efeitos de culturas de inverno sobre o rendimento de grãos e sobre a estatura de plantas de soja. Pesquisa Agropecuária Brasileira, Brasilia, v. 26, n. 5, p.729-735, 1991.

SIDIRAS, N.; DERPSCH, R.; MONDARDO, A. Influência de diferentes sistemas de preparo do solo na variação da umidade e rendimento da soja, em latossolo roxo distrófico (Oxisol). Revista Brasileira de Ciência do Solo, Viçosa, v.7, n.1,1983.

SILVA, A. R. B. Comportamento de variedades/híbridos de milho (Zea mays L.) em diferentes tipos de preparo do solo. Botucatu, 2000. Dissertação (Mestrado em Agronomia / Energia na Agricultura) Faculdade de Ciências Agronômicas, Universidade Estadual Paulista, Botucatu, 2000.

SORATTO, R. P.; CRUSCIOL, C. A. C. Nutrição e produtividade do amendoim em sucessão ao cultivo de plantas de cobertura no sistema plantio direto. Pesquisa Agropecuária Brasileira, Brasília, v.42, n.11, p.1553-1560, 2007.

STOLF, R. Cultivo mínimo para a cana-de-açúcar. Boletim Técnico PLANALSUCAR, Piracicaba, v.6, n.1, p.5-42, 1985.

TORRES, J. S.; VILLEGAS, F. Labranza reducida para renovación de plantaciones de caña de azúcar. In: ENCUENTRO NACIONAL DE LABRANZA DE CONSERVACIÓN, I, Anais... Villavicencio, Colombia, 1998. p. 337-352.

VILELA, E. F.; BÜLL, L. T. Avaliação do crescimento de plantas de milho em função de doses de potássio e estresse hídrico. Revista Brasileira de Ciência do Solo, [s.1.], v. 23, n. 2, p.281-289, jun. 1999.

VOSS, M.; SIDIRAS, N. Nodulação da soja em plantio direto em comparação com plantio convencional. Pesquisa Agropecuária Brasileira, Brasília, v.20, n.7, p.775- 782, 1985. 
